\title{
Using metagenomics to characterize organisms relevant for planetary protection
}

David C. Danko

Maria A. Sierra

James N. Benardini

Lisa Guan

Jason M. Wood

Nitin Singh

Arman Seuylemezian

Daniel J. Butler

Krista Ryon

Katerina Kuchin

Dmitry Meleshko

Chandrima Bhattacharya

Kasthuri J. Venkateswaran

Christopher Mason

\section{Video Byte}

Keywords: planetary protection, Spacecraft Assembly Facility, extremophile, microbial profiling, space, NASA, Microbiome

Posted Date: October 15th, 2021

DOl: https://doi.org/10.21203/rs.3.rs-969953/v1

License: (a) This work is licensed under a Creative Commons Attribution 4.0 International License. Read Full License 


\section{Abstract}

With an increasing number of spaceflights, microbial colonization of spacecrafts and assembly facilities is a concern. Planetary protection research focuses on developing technology for cleaning and sterilization, and clean rooms are the final step before spacecraft launch into space. But with their stringent air filtration and cleaning, Space Assembly Facility (SAF) rooms become a selective environment for microorganisms that can tolerate extreme cleaning methods. Because these microorganisms are likely low-abundance, current identification methods can struggle to characterize and profile SAF-residing microbes. A new study presents a comprehensive metagenomic framework to characterize microorganisms relevant for planetary protection. Researchers sequenced and analyzed 51 metagenomic samples from SAF clean rooms to identify microbes that could potentially survive spaceflight. They found evidence that clean rooms carry microbes with attributes that may make them problematic for space missions, including the ability to withstand extreme conditions, biofilm formation, spore-forming capacity, and resistance to radiation and desiccation. This framework will help researchers to better detect and quantify organisms that may threaten ongoing planetary protection goals, guiding the design of assembly facilities and future mission planning. 